\title{
Affirmative Action or Managing Diversity - What is the Future of Equal Opportunity Policies in Organisations?
}

\author{
Glenda Strachan, John Burgess and Anne Sullivan \\ Faculty of Business and Law \\ The University of Newcastle, NSW \\ Professor Glenda Strachan \\ School of Management \\ Griffith University \\ Nathan Campus \\ Brisbane Queensland 4111 \\ email: G.Strachan@griffith.edu.au
}

\begin{abstract}
$^{1}$
Equal employment opportunity policies were introduced in Australia from the 1980s in response to women's disadvantaged workforce position. Australia's unique form of affirmative action was underpinned by legislation and aimed to promote gender equity in the workplace via employer action. Throughout the 1990s there has been a policy shift away from collectivism towards individualism and away from externally driven and directed social programs at the workplace towards managerialist driven social programs. The main process for implementing progressive and inclusive equity programs at the workplace is through human resource management policies that link employment diversity to organisational objectives (for example, productivity and profitability). Programs titled Managing Diversity have been introduced into some organisations and today there are a variety of approaches towards equity policies in Australian organisations. This paper examines the principles behind affirmative action and the various interpretations of managing diversity and discusses the impact of these new policies. The paper proposes that a distinctive Australian version of managing diversity will develop in some organisations based on the legislative framework that has existed for nearly twenty years.
\end{abstract}

\footnotetext{
${ }^{1}$ This paper is based on research supported by an Australian Research Council Discovery Grant, 2002-2005, Chief Investigators Strachan and Burgess. This paper develops work in conference papers (2002 and 2003) by Strachan, Burgess and Sullivan.
} 


\section{Introduction}

Issues of equal employment opportunity (EEO) have been tackled in several ways in Australia. From the late 1960s successful equal pay cases were processed through the industrial relations system and from the 1980s discussion about women's wages widened to encompass a broader understanding of equal pay. Anti-discrimination legislation has been enacted at the federal level and in all states, beginning in 1975. This legislation seeks to redress essentially individual cases of discrimination after they have occurred and covers complaints on grounds such as sex, race, ethnicity, religion, family status, sexuality, disability.

Unique legislation designed to promote EEO was introduced in the 1980s and labelled affirmative action (AA). This legislative scheme grew from recognition of women's increasing workforce participation but unequal position in that workforce. The major piece of legislation, the Affirmative Action (Equal Opportunity for Women) Act 1986 (replaced by Equal Opportunity for Women in the Workplace Act 1999) related to women, and this legislation is the focus of the research. In the Australian context, AA "is about achieving equal employment opportunity for women...[and] to achieve this goal, the barriers in the workplace which restrict employment and promotion opportunities for women have to be systematically eliminated" (Affirmative Action Agency, 1990, p. 1).

Equal opportunity policies do not operate in a vacuum and they interact with other employment policies. The 1980s and 1990s have seen significant changes in the Australian industrial relations system and these have interacted with EEO policies. What was once a centralised system of conciliation and arbitration that operated via a semi-judicial authority has altered into a heterogeneous and fragmented system that emphasises workplace bargaining. The evolution to a decentralised industrial relations system corresponds to a period of declining trade union membership in which many women workers have limited voice and work in industries that have a high wage cost and do not have an easily measurable output. Despite this, the shift towards enterprise bargaining has been proclaimed as being sympathetic to women workers, notably through the development of "work and family" policies, that is, policies designed to enable employees to meet the demands of paid work and family commitments. In the 1990s government policies focused on giving parents the opportunity to choose between going to work or caring for children. With generous childcare support to low income workers, more recent policies have placed a greater emphasis on access to work (OECD, 2002).

In recent years, managing diversity (MD) programs have been promulgated. This paper begins to analyse what these programs can mean in an organisation and what options Australian organisations may choose to adopt. The importance of MD is being promoted in some human resource management (HRM) texts in a way that was never the case for EEO policies. For example, one recent Australian text asserts that

the bottom line is that to gain a competitive advantage in the next decade, companies must harness the power of the diverse workforce. These practices are needed, not only to meet employee needs, but to reduce turnover costs and ensure that customers receive the best service possible (De Cieri and Kramar, 2003, p. 28-29).

What might MD policies mean for an organisation and will they become part of its overall strategic direction? How will these policies affect the employment opportunities of women?

\section{Equal Employment Opportunity Policies in Australia}


The focus of the Affirmative Action Act was towards individual enterprise responsibility as opposed to legislative and economy wide standards. The Act compelled organisations with more than one hundred employees to implement an AA program. The legislation spelt out eight steps that organisations were to complete: assign responsibility for the achievement of EEO to senior staff and allocate sufficient personnel to undertake the task; undertake an analysis of the position of women in their organisation through examination of employment statistics and policies and consultation with women employees and trade unions. From this analysis the company was required to devise a program which addressed some of the problems identified and set targets against which future progress could be judged (Strachan, 1987). The legislation preserved an individual rather than a collectivist focus in its reliance on the merit principle (Thornton, 1990, p. 246). Affirmative action in Australia has been characterised as an inclusionary or incorporation model as it relies on the underlying principle of bringing women up to equality with men (Bacchi, 1996, p. 84).

The implementation of EEO principles presumed good corporate citizenship as there were no explicit national standards and the penalties for non-compliance were weak: non-submission of a report meant that the company might be named in parliament. In 1992 the government added the sanction that companies breaching the legislation were ineligible for federal government contracts or specified industry assistance. It is likely that this sanction was never used (no data was collected by the AA Agency).

With the election of a Coalition (conservative) federal government in 1996 the legislation was reviewed and changes initiated on 1 January 2000. In the Equal Opportunity for Women in the Workplace Act 1999 the guidance given to employers on how to implement a program was reduced and the previous eight steps of an affirmative action program were deleted, removing the emphasis on senior management support, allocation of resources, consultation with women and trade unions and setting specific targets. To comply with the new Act, organisations have to take actions on the priority issues identified when undertaking an organisational analysis. Organisations should develop a workplace program by:

- preparing a workplace profile

- analysing the issues for women in the workplace, considering each of the employment matters, to identify their priority issues

- take action to address the priority issues

- evaluating the effectiveness of the actions.

Organisations are required to address seven employment matters within their analysis. These are:

recruitment procedure and selection criteria for appointment or engagement of employees

promotion, transfer and termination of employment of employees

training and development for employees

work organisation

conditions of service of employees

arrangements for dealing with sex-based harassment of women in the workplace

arrangements for dealing with pregnant, potentially pregnant employees and employees who are breastfeeding their children (EOWA, 2000, p. 13).

When reports are considered by the Agency the seven employment matters are analysed in order to evaluate the progress of the EEO program. Reporting is still required on an annual basis (although this can be waived under certain circumstances) but the reporting form is no longer prescriptive. In addition, since 1999 organisations have been assessed only on the basis of whether the report meets the minimum 
requirements of the Act, rather than a grading of the quality of reports that occurred in the mid-1990s (Strachan and Burgess, 2000).

The Affirmative Action Act proposed the development of goals and targets against which progress could be measured, however, in the Equal Opportunity for Women in the Workplace Act 1999 goals and targets have been removed and the emphasis on collection of employment statistics weakened. In this way the Australian system is moving closer to models in other English-speaking countries (Strachan, Burgess and Sullivan, 2002) with even more emphasis on management decisions and less direction from the Act. There are now less prescriptive requirements on supplying workforce data in a set format in Australia, a move towards the British voluntary system Opportunity Now, where organisations seem reluctant to complete the workforce data section of the Benchmarking Survey (Opportunity Now, 2001, p. 56).

In some ways the introduction of the new legislation in Australia may have lessened the role of senior management. In the Affirmative Action Act senior management's role was stated up front in order to convince employees that changes to an organisation's policies and practices were good for the company. However, changes to EEO legislation in Australia have seen a shift in emphasis away from top management. The old legislation specified that an organisation was to assign responsibility for the achievement of EEO to senior staff as one of the steps to an affirmative action program. This step was included for management to show that clear support for affirmative action was demonstrated at a senior level with the provision of adequate resources to achieve the goals of the program.

\section{The Family Friendly Workplace Agenda}

The emergence of the concept of work and family policies in the 1990s has been pursued mainly through government, business and trade union encouragement to pursue policies that allow for the individual worker to combine work duties and family commitments. Recently these have been characterised as Work/Life Issues and in a recent survey 205 organisations reported that a variety of flexible work arrangements had reduced staff turnover and produced other business benefits (Managing Work Life Balance, 2003). These changes have increased the variety of employment arrangements and have been linked to the decentralised industrial relations regime. Some have been implemented via industrial agreements while the majority appear to be internal organizational policies. There are doubts over how those with little bargaining power, generally the low paid and those in insecure employment, can effectively utilise enterprise bargaining as an instrument for the better integration of work and family responsibilities (Barrera and Robertson, 1996). The impression from the enterprise bargaining experience is that family friendly work has more to do with cost reduction and improved inter-temporal workforce deployment than it has to do with genuine family friendly work arrangements (Strachan and Burgess, 1998b).

It is difficult to assess how beneficial many of the alleged family friendly work arrangements have been to women workers. Reference to the federal agreements report for 2000/2001 indicates that there appears to be very little progress through enterprise bargaining with respect to family friendly work arrangements. In 2000/01 the following arrangements were in less than five per cent of agreements: unlimited sick leave, all purpose paid leave, paid family leave, extended unpaid parental leave, paid adoption leave, paid paternity leave, home based work, child care provisions and job sharing. The two main provisions were access to other leave for caring purposes (19 per cent) and part-time work (25 per cent). Not all part-time work is voluntary and part-time shifts may be very unfriendly for working 
parents. Making available leave for caring purposes is an extremely modest arrangement from employers.

Overall there appears to be modest advances with respect to enterprise bargaining developing and delivering family friendly work arrangements. This agenda largely excludes small businesses and casual workers - both dominated by women - who have a relatively low incidence of representation in federal agreements. It is also based on the goodwill and discretion of managers. Even if family friendly work arrangements are included in an agreement it is not clear who has access to conditions and under what circumstances they have access to conditions. In order to participate in the family friendly work agenda you require voice, bargaining power and an ability to demonstrate that such arrangements are also beneficial for business.

\section{Managing Diversity}

In recent years a new term "managing diversity" has come into use. The MD agenda is one that has come to Australia from the USA as an HRM workplace strategy. Pressures in competing in a global marketplace confront USA businesses and

organisations are dealing with diversity in their client and customer populations as well as among their employees. Responding effectively to a more heterogeneous customer base is a requirement in the growing service sector....Moreover, workforce diversity presents a challenge to organisations that are devolving a variety of responsibilities to decision-making teams, which increasingly consist of individuals of varying backgrounds (Agocs and Burr, 1996, p. 31).

In the USA, the popularity of MD reflects a search by organisations for an alternative to the contentious affirmative action legislation and as a way to broaden what was seen as a narrow AA agenda that concentrated on hiring. MD is seen as a way to address issues of retention, integration and career development (Agocs and Burr, 1996, p. 34).

The term "managing diversity" or its variants has no specific definition, unlike AA or EEO in Australia where we can look to legislative definitions or explanations by monitoring agencies such as the EOWA. There appears to be almost as many definitions as there are articles on MD and many HRM texts now have a chapter on MD. There is some repetition in many of the definitions. Bartz et al (1990, p. 321) state that MD involves

understanding that there are differences among employees and that these differences, if properly managed, are an asset to work being done more efficiently and effectively. Examples of diversity factors are race, culture, ethnicity, gender, age, a disability, and work experience.

Another definition often used asserts that

the basic concept of managing diversity accepts that the workforce consists of a diverse population of people. The diversity consists of visible and non-visible differences which will include factors such as sex, age, background, race, disability, personality and workstyle. It is founded on the premise that harnessing these differences will create a productive environment in which everybody feels valued, where their talents are being fully utilized and in which organizational goals are met (Kandola and Fullerton, 1994, p. 8).

It is common in the literature to read that MD is a higher or better level of organisational program than AA. What are often characterised as "older" concepts of EEO were based on recognition of 
employment discrimination targeting groups with specific characteristics such as gender, ethnic origin, disability (for example, "managing diversity seeks to build on many of the good initiatives undertaken under the banner of equal opportunities" \{Gill, 1996, p. 34\}). Maxwell et al (2001, p. 469), speaking of Britain, suggest that there are two ways in which MD is differentiated from EEO: the emphasis on a positive perspective on staff differences versus the negative perspective of disadvantage; the inclusion of diversity factors beyond those included in EEO legislation.

These arguments are based on an analysis of EEO and AA in the USA and Britain and highlight a clear difference between the USA and British EEO heritage and that of Australia. In Britain, the response to the achievement of equal opportunity has been different to that in Australia. It is essentially a legislative compliance model with equal pay legislation was passed in 1970 and sex discrimination legislation in 1976. The focus of this legislation is on remedying individual complaints rather than requiring employer action to promote equality. Although some employer action is required by legislation on religious discrimination in Northern Ireland and by public sector employers in respect of race, the British Government has rejected calls for such an approach with regard to gender. A voluntary management driven program somewhat akin to Australia's AA legislation has been promoted throughout the 1990s but coverage is not large and the outcomes difficult to determine (Strachan, Burgess and Sullivan, 2002).

This history has influenced some of the responses to MD in Britain. Wilson and Iles (1999, p. 30) assert that EEO legislation has not produced race or gender employment equality and they have looked towards the concept of MD. They propose that "equal opportunities - the old paradigm" is externally driven and rests on moral and legal arguments and perceives equal opportunity as a cost with difference perceived as problematical. "Managing diversity - the new paradigm" is internally driven, rests on a business case and perceives MD as an investment and difference is perceived as an asset (Wilson and Iles, 1999, p. 31). In supporting MD for the UK public sector, Wilson and Iles (1999) highlight four key differences between the EEO and MD agendas:

a. EEO is externally driven, based on legal or moral arguments, while MD is internally driven, based on organisational objectives linked to the "business case" for equality, for example profitability.

b. The EEO agenda is formal and minimalist - organisations need only reach set required targets or outcomes. The MD agenda is not restrictive or minimalist and participating in the agenda is an investment tied to organisational goals.

c. The EEO agenda uses a white, male, full-time, heterosexual norm and fits other groups into this norm. The MD agenda embraces diversity and the mainstream is expected to encompass the diversity agenda.

d. The EEO agenda is narrowly focussed towards certain groups such as women or racial groups, the MD agenda goes beyond this narrow group focus.

In the HRM literature there is extensive analysis of the details of the MD workplace strategy. There is discussion and analysis of the meaning of diversity, the support mechanisms (for example, training and mentoring) necessary for developing and implementing diversity programs, the management of diversity programs, the outcomes of diversity programs for employees and for organisations, and the limitations of diversity programs (Dass and Parker, 1999; Moore, 1999; Iverson, 2000; Easley, 2001). The MD agenda attempts to be responsive to personal differences and to aspirational differences. In turn, this sensitivity can reduce labour turnover and absenteeism, improve productivity and commitment, and hence service the operational goals of the employing organisation. 
The language of MD is constructed around the key values of business and being tied to the business case means that the MD program is dependent on business conditions. What business can afford this year may not be able to be afforded next year. It also tends to treat businesses as homogeneous. There may be extensive and progressive MD programs, but there may also be ineffective and superficial MD programs that give the appearance of business support for workplace equity objectives. Employees are represented as being diverse yet managers and businesses are seen as being homogeneous and benevolent.

Commenting on the USA, Agocs and Burr (1996, p.34) place MD as "one of the many interventions in the organizational development...family" and state that it is "primarily concerned with improving interpersonal and inter-group communication and relationships in the workplace". They assert that "the norm is understood to be the traditional white able-bodied male employee or manager, and 'diversity' refers to 'the others' "(Agocs and Burr, 1996, p. 39). There is no recognition of systemic discrimination. They conclude that

affirmative action is intended as a response to and remedy for past and continuing discrimination against specific disadvantaged groups. In contrast, the goals of managing diversity are vague, but have to do with changing attitudes and interpersonal behaviours in the direction of greater acceptance by traditional employees of the diversity that has resulted from demographic change, and from the entry of non-traditional employees into the workplace. Thus managing diversity and affirmative action are not substitutes for each other, nor do they lie on a continuum, since they address different issues (Agocs and Burr, 1996, p. 39).

On the other hand, some commentators see MD as merely a repackaging of equal opportunity policies (Wilson and Iles, 1999, p. 40).

\section{Managing Diversity: The Australian Response}

Australia's unique response to the discrimination and under-utilisation of women in the workforce will influence the usage of MD in Australia. Industrial relations scholars are familiar with the concept that each country has its own unique system of labour relations. The same is true of equity initiatives. While both systems are intertwined and influenced by international trends, the response is not uniform from country to country. Therefore the history of Australia's EEO approaches will influence the form of MD and its spread.

The criticisms made of AA and EEO in the USA and Britain cannot be transferred blindly to the Australian scene. AA and EEO in Australia are distinctly different programs from those in these other countries. While Australia has had specific anti-discrimination legislation it has also had a widespread workplace program with a legislative base that promotes at least gender equity. This has meant that there is much more attention paid to issues such as retention of women employees and, in the 1990s, the new discourse of accommodating work and family (Strachan and Burgess, 1998a) has meant that some organisations have looked to different working patterns (workstyles) for their employees in a way that is not specifically gendered. There has always been a business case argument attached to EEO legislation and policies in Australia along with a social justice argument. The cost of losing employees and the under-utilisation of skills is highlighted in these arguments (EOWA, 2003).

We predict that there will be a range of responses in Australia that will include rebadging AA or EEO programs as MD programs through to a different approach that lacks an understanding of systemic 
discrimination. Suncorp Metway Ltd, Banking and Finance, for instance, identifies the implementation of a Diversity Strategy in its report to EOWA (Suncorp Metway Ltd, 2002). The key priorities of this strategy are leadership, compliance, flexible working arrangements, work/life balance, women in management. The report is similar in analysis and intent to those of other companies that have clear goals and display an understanding of discriminations issues. Therefore it may be seen as a rebadging of part of their EEO strategy.

This is not always the case. The MD agenda supplants EEO by stressing individualism and the convergence of the organisations objectives with those of the individual worker. Not surprisingly, under the current Federal government the MD program is prominent across the Australian Public Service. Reference to the Department of Employment and Workplace Relations website reveals the department's workforce diversity strategy (Department of Employment and Workplace Relations, 2002). Workplace diversity is about "recognising difference" and ensuring that the workplace is "free from discrimination and harassment". MD can achieve better outcomes for workers, the organisation and clients - it is a win-win situation. Bacchi's (2000, p. 74-78) analysis of changes in policy in the Australian Public Service emphasises departmental flexibility in responses to equity issues and she concludes that changes to the Public Service Act have reduced scrutiny in the area of equal opportunity (Bacchi, 2000, p. 77).

In recent years management texts have emphasised the value of employees in achieving businesses success: "the people doing the work of an organisation are an important part of creating competitive advantage" (De Cieri and Kramar, 2003, p. 248). MD emphasises this value. A recent Australian HRM textbook describes MD "as a process of management built on a set of values which recognise that the differences between people are a potential strength for an organisation" (De Cieri and Kramar, 2003, p. 248). It refers to "the vast array of personal and cultural differences that constitute the human race" (De Cieri and Kramar, 2003, p. 250), thus picking up the definitions commonly used overseas. De Cieri and Kramar (2003, p. 27) list a range of activities involved in managing cultural diversity:

ensuring that HRM systems are bias-free, facilitating higher career involvement of women, promoting knowledge and acceptance of cultural differences, ensuring involvement in education....and dealing with employees' resistance to diversity.

These are important issues as the ways in which diversity issues are managed "has implications for creativity, problem solving, retaining good employees and developing markets for the firm's products and services" (De Cieri and Kramar, 2003, p. 27).

The MD program has similarities to the family friendly work agenda that supports the enterprise bargaining agenda. First, it is management centred. Managers can develop arrangements that benefit both the employer and the employee. It represents another variation of the business case for family friendly work arrangements and for enterprise bargaining. A workplace centred approach is proclaimed as the most effective means for realising diversity objectives. Second, it is individualist. Differences in family arrangements support the family friendly work agenda while differences across the workforce support the MD agenda. Third, there are no norms. What constitutes a suitable family friendly work arrangement? What constitutes a suitable MD arrangement? In a sense it can be proclaimed that the status quo represents the MD agenda. Everyone's difference has been incorporated into the outcomes. It is also not clear how differences can be reconciled within the MD agenda. Fourth, it is a voluntary agenda so participation and inclusion is not required for all organisations. By implication it is an agenda 
that only encompasses those organisations that have an HRM department and sufficient workers to support HRM practices - that is, by implication it excludes small businesses (as does EEO legislation).

Bacchi (2000) argues that the MD program attempts to hide inequalities under the umbrella of "difference" and to by-pass fundamental equity programs and social policy objectives. This entails leaving equity programs to business and to reducing the extent of external scrutinisation of business employment practices. If businesses have an MD program then there is no need for EEO and, of course, for any external scrutiny of business employment practices. So while EEO had many gaps it did force (large) businesses to articulate a gender equity agenda and to report on the progress with respect to this agenda. Reports were subject to public scrutiny and assessment. At a fundamental level MD treats difference as a virtue and proclaims differences in employment practices and employment outcomes as a virtue. What may appear to be fundamentally discriminatory workplace outcomes by gender or ethnicity can be presented as a considered outcome that accounted for difference.

However, Agocs and Burr (1996) and Kramar (1998, p. 134) do not consider MD as the next generation of AA but rather as an approach to management. Kramar (1998, p. 141) says that the stimulus for MD will be the continuing search for organisational effectiveness, a clearly different motivation to AA:

diversity management will provide an opportunity to manage a workforce which emphasizes organizational and individual performance and at the same time acknowledges individual needs. This approach to management requires building a culture which supports diversity among organizational contributors.

If $\mathrm{MD}$ is seen in this light then is it possible to have both the Australian AA/EEO approach and a philosophy of valuing difference in staff, that is MD, operating within an organisation?

\section{The Future of Employment Equity Policies in Australia}

There appears to be a continuity and consistency in the gender equity policy program emerging in Australia over the past decade. EEO and its program of setting, monitoring and achieving gender equity outcomes has given way to a more voluntarist, less extensive and less proscribed agenda where business is left to manage its gender equity programs with less intrusiveness. The deletion of the step specifying goals and targets in the new EEO Act has reduced the emphasis on outcomes and other changes have allowed greater management discretion in the development of equity policies. However, the legislation is still more prescriptive and broad in terms of the employment issues it addresses than in Britain or the USA.

The legislation in Australia only set reporting and gender policy requirements for relatively large organisations. As a result many women workers, especially casuals, were marginalised. With the shift towards individualism and voluntarism that is encompassed in the family friendly work and MD agendas, the scope and application of the gender policy program has become even more problematical, voluntarist and private. It is now in the hands of workplace managers with trade unions all but being written out of the EEO and MD agendas. These are largely business or managerialist (in the case of the public sector) centred programs.

If the basis for AA/EEO programs and MD are fundamentally different, can the two types of programs co-exist in an organisation? Is it possible for Australian organisations to shape MD in a specific Australian direction? Can it exist in a multitude of forms? Can MD place equity issues on the Board or senior management agenda in a way that AA did not usually achieve? Or will it do this at the 
price of a lack of understanding of systemic discrimination and the differential impact of this on certain groups of workers?

One of the goals of proponents of AA in Australia was always to have senior management involvement and support. In the past two decades changes in the personnel functions of organisations and their development into HRM departments has brought a change of focus so that many management texts advise that HRM managers are an integral part of the formulations and implementation of an organisation's strategic goals. There is a realisation that employees are critical in the achievement of an organisation's objectives and are a major part in its competitive advantage and therefore the policies that recruit and maintain this workforce are rightly part of senior management consideration (De Cieri and Kramar, 2003, chapters $1 \&$ 2). The HRM function is in transition from an administrative role to a strategic business partnership (De Cieri and Kramar, 2003, p. 23). It may be that in this changed context and greater recognition of the need for strategic planning that equity issues can achieve a presence in the highest levels of organisational thinking that has not occurred in the past. But as HRM issues are devolved to line managers then it is also important that all levels of management are conversant with the issues.

EEO policies have always been more prevalent in large organisations. If MD policies are implemented it will be in these organisations with HRM departments. Under the current legislative situation these organisations will also respond to the requirements of the EEO Act and some will wish to excel and win prizes in the various schemes for best EEO organisation. These organisations are highly unlikely to adopt the USA focus of managing diversity without continuing with the Australian EEO programs. In this way it is likely that MD will be adopted as a strategy for enhanced organisational effectiveness and may be grafted onto EEO policies.

It is quite clear when sampling annual reports to the EOWA that many organisations are reporting in a minimal way so that they meet the minimum requirements of the Act. Overall, most of their HRM policies do not display an understanding of EEO or MD issues. These organisations are not likely to be the ones who embrace MD unless they change their thinking about conditions for employees generally. As noted in the annual reports of the AA Agency in the 1990s, certain industry sectors lag behind others in their understanding and adoption of EEO policies.

In Australia and Britain from the mid-1990s, and increasingly in the last few years, the dominant discourse in employment is around the issues of combining paid work and family care. These work and family issues have gained widespread public recognition in Australia and have resulted in some minimum conditions (for example, unpaid parental leave and use of sick leave to care for family members), largely through decisions of the industrial relations commissions. Yet implementing these in a cohesive way to the benefit of employees is really reliant on an EEO plan within an organisation. The discourse has moved from being one of EEO that is based on an analysis of gendered workplace discrimination to that of "work and family" and "family-friendly" organisations - a notion that it is hard to disagree with and one that is more acceptable to a conservative government analysis of women and society (Ostenfeld and Strachan, 1999).

In an era of increasing emphasis on quality assurance of products and services and widespread views that employees are an important component in the achievement of competitive advantage, it is concerning that MD policies generally come without any measurable goals and objectives. The EEO legislation in Australia emphasised collection of data on which to base programs and organisations could 
develop performance indicators to measure progress towards a defined goal. How do you measure the success of MD without clear goals and performance indicators?

It is clear that there is no automatic path in EEO that leads to improved performance over time. Organisations can move in any direction on a performance scale. Analysis of reports to the AA Agency in Australia has shown that there has been no great move for organisations to gain a higher rating, and the proportion of firms located within the three levels of assessment remained relatively stable (Strachan and Burgess, 2000; Strachan, Burgess and Sullivan, 2001). More detailed analysis of outcomes and the role of EEO policies within organisations will rely on organisational case studies. If organisations in Australia embrace MD then it will be an Australian variant of MD and is likely to be operated in concert with the EEO policies in place.

\section{References}

Affirmative Action Agency (1990). Taking Steps: Employers' Progress in Affirmative Action, AGPS, Canberra.

Agocs, C. and C. Burr (1996), 'Employment Equity, Affirmative Action and Managing Diversity: Assessing the Differences', International Journal of Manpower, 17, 4/5, pp. 30-45.

Bacchi, C. (1996). The Politics of Affirmative Action. 'Women', Equality and Category Politics, Sage, London.

- (2000), 'The Seesaw Effect: Down Goes Affirmative Action, Up Comes Managing Diversity', Journal of Interdisciplinary Gender Studies, 5, 2, pp. 64-83.

Barrera, S. and R. Robertson (1996), 'Bargaining at the Workplace: Issues for Women Workers', in D. Mortimer, P. Leece and R. Morris eds. Workplace Reform and Enterprise Bargaining: Issues, Cases, Trends. Harcourt Brace and Co., Sydney, pp. 259-268.

Bartz, D., L. Hillman, S. Lehrer and G. Mayburgh (1990), 'A Model for Managing Workforce Diversity', Management Education and Development, 21, 5, pp. 321-326.

Dass, P. and B. Parker (1999), 'Strategies for Managing Human Resource Diversity: From Resistance to Learning', Academy of Management Executive Review, 13, 2, pp. 68-80.

De Cieri, H. and R. Kramar (2003). Human Resource Management in Australia, McGraw Hill, Sydney.

Department of Employment and Workplace Relations (2002). 'Workplace Diversity Strategy: 1999-2002', Interet address: <http://www.dewr.gov.au>.

Easley, C. (2001), 'Developing, Valuing and Managing Diversity in the New Millenium', Organisational Development Journal, 19, 4, pp. 38-50.

Equal Opportunity for Women in the Workplace Agency (EOWA) (2000). EOWA Annual Report 1999-2000, AGPS, Canberra.

-. (2001). EOWA Annual Report 2000-2001, AGPS, Canberra.

- (2003). EOWA website <http://www.eowa.gov.au> accessed 5 January.

Gill, P. (1996), "Managing workforce diversity - a response to skill shortages?" Health Manpower Management, 22, 6, pp. 34-37.

Iverson, K. (2000), 'Managing for Effective Workforce Diversity', Cornell Hotel and Restaurant Administrative Quarterly, 41, 2, pp. 31-38.

Kandola, R. and J. Fullerton (1994). Managing the Mosaic-Diversity in Action. IPD, London.

Kramar, R. (1998). 'Managing Diversity: Beyond Affirmative Action in Australia', Women in Management Review, 13, 4, pp. 133-142.

Managing Work Life Balance (2003) Work/Life Initiatives: The Way Ahead Report on the Year 2003 Survey, <http://www.worklifebalance.com.au>.

Maxwell, G., S. Blair and M. McDougall (2001), 'Edging Towards Managing Diversity in Practice', Employee Relations, 23, 5, pp. 468-482.

Moore, S. (1999), 'Understanding and Managing Diversity Among Groups at Work: Key Issues for Organisational Training and Development', Journal of European Industrial Training, 23, 4/5, pp. 208-217.

Napoli, J. (1994). Work and Family Responsibilities: Adjusting the Balance. CCH, Sydney.

Opportunity Now (2001). Benchmarking Report and Index 2001. Business in the Community, London. 
Organisation for Economic Co-operation and Development (OECD) (2002). Babies and Bosses: Reconciling Work and Family Life. OECD, Paris. Volume 1.

Ostenfeld, S. and G. Strachan (1999), 'Women's Work and the Howard Government: The Impact of Social Conservatism on Australian Industrial Relations', Policy, Organisation and Society, 18, pp. 16-38.

Strachan, G. (1987), 'Equal Employment Opportunity and Industrial Relations: The Path to Equality', Journal of Industrial Relations, 29, 2, pp. 190-206.

Strachan, G. and J. Burgess (1998a), 'The 'Family Friendly' Workplace: Origins, Meaning and Application at Australian Workplaces', International Journal of Manpower, 19, 4, pp. 250-265.

-. (1998b), 'Towards a New Deal for Women Workers in Australia? Growing Employment Share, Enterprise Bargaining and the 'Family Friendly' Workplace', Equal Opportunities International, 17, 8, pp. 1-13.

- (2000), 'W(h)ither Affirmative Action Legislation in Australia?', Journal of Interdisciplinary Gender Studies, 5, 2 , pp. 46-63.

Strachan, G., J. Burgess and A. Sullivan (2001), No Longer 'Special Women's Business': Affirmative Action in Australia in 2001', in Di Kelly (ed) AIRANNZ 2001: Proceedings of the 15 ${ }^{\text {th }}$ AIRANNZ Conference, 2, pp. 159-166.

- (2002), 'Equal Employment Opportunity in Australia and Britain: Policy Approaches', paper presented at the Employment Research Unit, Cardiff University, $17^{\text {th }}$ Annual Conference, 12-13 September.

Suncorp Metway Ltd. (2002). Public Report submitted to EOWA. Internet address: <http://www.eowa.gov.au> accessed 20 December.

Thornton, M. (1990). The Liberal Promise: Anti-Discrimination Legislation in Australia. Oxford University Press, Melbourne.

Wilson, E. and P. Iles (1999), 'Managing Diversity - An Employment and Service Delivery Challenge', The International Journal of Public Sector Management, 12, 1, pp. 27-48. 